\title{
From Employee Perceived HR Practices to Employee Engagement: The Influence of Psychological Empowerment and Intrinsic Motivation
}

\author{
Jie $\mathrm{HE}^{1, \mathrm{a}}$ \\ ${ }^{1}$ No.59, Zhongguancun Street, Haidian District, Beijing 100872, P.R. China \\ ahejieflying@gmail.com
}

Keywords: Employee perceived HR practices, Psychological empowerment, Intrinsic motivation, Employee engagement.

\begin{abstract}
In this study, we developed and tested a theory of how employee perceived human resource (HR) practices affect employee psychological empowerment that facilitates intrinsic motivation and resultant employee engagement in the work. Based on self-determination theory, employee engagement was rooted in the basic psychological needs satisfaction including competence, autonomous and relatedness. A survey of 485 employees from financial firms showed that the employee perceived HR practices were positively related to the psychological empowerment including the feeling of meaning, impact, autonomy and competence. In turn, the psychological empowerment was related to intrinsic motivation, a relationship that predicted employee engagement.
\end{abstract}

\section{Introduction}

In the current economy, the firms not only have to recruit top talent, but must inspire employees to be engaged and apply their full capabilities to their work. Employees exhibit engagement when they become physically involved in tasks, are cognitively focused, attentive and vigilant and are emotionally connected to their work [1,2]. And considerable evidence shows that employee engagement is positively related to customer satisfaction-loyalty, customer ratings, profitability, and productivity [3].

However, while engaged employees are characterized by high levels dedication to their work, there are many organizations face the depletion of human employee engagement at work, or called human employee engagement crisis, such as burnout, exhaustion currently [4]. Unfortunately, China has the lowest rates of employee engagement in the world, and just $6 \%$ of Chinese workers are engaged in their jobs according to the survey conducted by Gallup in 2013 [5].

It is not surprising that developing employee engagement is an organizational priority in practice. How to fuel the employees' passion so that improve employee engagement is the great challenge for HRM.

\section{Theory and Hypotheses}

Employee engagement first mentioned by Kahn (1990) was defined as the simultaneous employment and expression of a person's "preferred self" in task behaviors that promote connections to work and to others, personal presence (physical, cognitive, and emotional) and active full role performances" (p. 700). Rich proposed an operationalization of this construct based on Kahn's theoretical model. The three dimensions of engagement including physical aspect, emotional aspect and cognitive aspect would adequately reflect employee engagement. Followed Kahn and Rich, we defined that employee engagement represents the simultaneous investment of cognitive, affective and physical energies in the work.

The evidence shows that HR practices are positively associated with employee engagement [6]. Based on self-determination theory, Meyer \& Gagne (2008) assumed that need satisfaction is an important mediator in the relation between environmental impacts and autonomous effort in the work [7]. And the vitality and energy engaged in the work are enhanced by the satisfaction 
associated with basic psychological needs for relatedness, competence and autonomy. Accordingly, we need to build a model linking HR practices and employee engagement and explain how and why perceived HR practices influence employee engagement in the work. Moreover, there are differences between implemented HR practice and employee experienced HR practices, and it's necessary to examine the employee perceived HR practices to individual employees' psychological process through which influence employees' motivation and behaviors in the work [8].

\section{Influence of Perceived HR practices on psychological empowerment and intrinsic motivation}

The employee perceived HR practices focused on extensive training, performance feedback, performance contingent compensation and employee participation will lead employee to view their work environment as providing opportunities for capability enhancing and self-direction at work leading to psychological empowerment [9]. Perceived extensive training may improve employees' competence in the work; performance-oriented appraisal, internal promotion may help employees perceive the tasks to be important and meaningful; participation and increased discretion in the work may enhance employee's perceived autonomous and impact. We argue that perceived HR practices are positively related to psychological empowerment included meaning, competency, autonomous and impact in the work.

Hypothesis 1:The employee perceived HR practices are positively related to psychological empowerment.

People have the innate psychological needs for competence (experiencing oneself as capable and to play a role in performance), relatedness (a feeling of belonging to and participating in mutual respect and caring) and autonomy (participating in choices and having power to decide one's actions) [10]. The psychological empowerment emphasizing the feeling of competence, autonomy, meaningful and impact in the work means the basic psychological need satisfied [11]. Intrinsic motivation refers to the involvement in an activity for its enjoyment [12]. And psychological empowerment influenced by external practices is presumed to be a proximal cause of intrinsic motivation [13]. According to SDT theory, the activities that satisfy basic psychological needs are the source of intrinsic motivation.

Hypothesis 2: The psychological empowerment mediated the relationship between perceived HR practices and intrinsic motivation.

\section{Psychological empowerment, intrinsic motivation and employee engagement}

Considerable evidence showed that intrinsic motivation plays an important role in determining behaviors that may result in employee engagement, and the key to engagement is satisfaction of basic psychological needs for competence, autonomy and relatedness. Individuals are more engaged in the work where their psychological needs are satisfied and inner-directed, interested in of fascinated with a task [14].

As a kind of autonomous behavior, employee engagement be fostered based on the understanding of the value of work and the confidence of competence and autonomy. Feelings of autonomy, high-quality relations, positive meaning and impact in the work will increase employees' vigor, and enthusiasm in the work through enhancing their interesting and enjoyment in the work.

The intrinsic motivation plays a mediating role between the psychological empowerment and employee engagement. When employees find that they are more capable and influence the outcomes at a greater level, they are more likely to be enthusiastic about their work [15]. And employees feel that he or she has the ability to implement a task successfully, employee will pay more attention in the work persistently. According to self-determination theory, we expected the following:

Hypothesis 3: the employee perceived HR practices are positively related to employee engagement through psychological empowerment and intrinsic motivation. 


\section{Method}

\section{Sample and Procedures}

We tested the proposed theoretical framework using date from financial firms in China. About 485 employees from 300 firms participated in the study. Participants included male and female constituting $53.6 \%$ and $46.4 \%$ respectively. On average, they were 31.4 years old and had 4.84 years tenure, and were predominately bachelors and masters $(90.9 \%)$.

\section{Measures}

Participants rated their own perceived HR practices, psychological empowerment, intrinsic motivation, and employee engagement using a five-point Likert scale that ranged from "strongly disagree"(1) to "strongly agree"(5).

To measure the employee perceived HR practices, we drew from Sun et al. (2007) research [16]. This scale showed good reliability, and the Cronbach's $\alpha$ was 0.86 . We measured psychological empowerment with a 12-itm scale adapted from Spreitzer (1995) [17]. The Cronbach's $\alpha$ was 0.89. For the intrinsic motivation, we drew from Tremblay et al. (2009) measure of intrinsic motivation theoretically grounded in self-determination theory [18]. The Cronbach's $\alpha$ was 0.83. We measured the employee engagement with a 18-item scale adapted from Rich et al. (2010). The Cronbach's $\alpha$ was 0.93 . Because past studies have indicated that demographic variables may be related to employees' behavior [19]. Thus, age, gender, education level position and tenure, and the ownership and industry of the firm employees belongs to were included as control variables in this study.

\section{Results}

The means, standardized deviations, correlations and reliability statistics of key variable are presented in table 1. As shown in the table, the key variables all possess an acceptable degree of internal consistency reliability. We can assess the association between the outcome variables employee engagement in the work and variables of employee perceived HR practices, psychological empowerment and intrinsic motivation.

Table 1. Descriptive Statistics and Correlations for Key Study Variables

\begin{tabular}{ccccccc}
\hline & Mean & SD & 1 & 2 & 3 & 4 \\
\hline 1perceived HR practices & 3.66 & 0.54 & $(0.86)$ & & & \\
2 psychological & 3.83 & 0.56 & $.712^{* *}$ & $(0.89)$ & & \\
empowerment & & & & & \\
3 intrinsic motivation & 4.00 & 0.70 & $.607^{* *}$ & $.663^{* *}$ & $(0.83)$ & \\
4 engagement & 4.03 & 0.54 & $.587^{* *}$ & $.730^{* *}$ & $.661^{* *}$ & $(0.93)$ \\
\hline
\end{tabular}

Note. Reliability coefficients are shown in parentheses on the diagonal. * $\mathrm{p}<.05,{ }^{* *} \mathrm{p}<.01$, $* * * \mathrm{p}$ $<.001$, two tailed.

We present the regression results with perceived HR practices, psychological empowerment, and intrinsic motivation as the dependent variable in Table 2. As shown in Mode 2 of Table 2, we found that the perceived HR practices was significantly related to psychological empowerment $(\beta=0.57$, $\mathrm{p}<0.001)$. Next, as shown in model 3, we found that the relationship between perceived HR practices and intrinsic motivation was dramatically reduced but still significant $(\beta=0.28, p<0.001)$.

Next, we examined the combined mediating effects of psychological empowerment and intrinsic motivation on the relationship between perceived HR practices and employee engagement. We first examined the relationships between perceived HR practices and employee engagement. As shown in model 7 , the perceived HR practices was significantly related to engagement $(\beta=0.52, p<0.001)$. 
In the second, we found significant relationships between the perceived HR practices and psychological empowerment, and intrinsic motivation in models 2 and 4. Finally, we examined changes in the effect of perceived HR practices when psychological empowerment and intrinsic motivation were added to the regressions predicting engagement in the third step. The results showed that the relationship between perceived HR practices and engagement was lower and no longer significant in model $9(\beta=0.06)$. All hypotheses were supported.

Tab. 2 Regression of perceived HR practices and employee engagement

\begin{tabular}{|c|c|c|c|c|c|c|c|c|c|}
\hline \multirow[t]{2}{*}{$\begin{array}{l}\text { Dependent } \\
\text { variable }\end{array}$} & \multicolumn{2}{|c|}{$\begin{array}{l}\text { Psychological } \\
\text { empowerment }\end{array}$} & \multicolumn{3}{|c|}{ Intrinsic motivation } & \multicolumn{4}{|c|}{ Employee engagement } \\
\hline & Mode1 & Mode 2 & Mode3 & Mode4 & Mode5 & Mode6 & Mode7 & Mode8 & Mode9 \\
\hline Gender & -0.05 & -0.03 & -0.05 & -0.03 & -0.02 & -0.08 & -0.06 & -0.04 & -0.04 \\
\hline Age & 0.07 & 0.08 & 0.01 & 0.02 & -0.02 & 0.06 & 0.07 & 0.02 & 0.02 \\
\hline Tenure & -0.03 & -0.03 & -0.05 & -0.06 & -0.04 & 0.02 & 0.02 & 0.04 & 0.05 \\
\hline Education & -0.03 & -0.07 & -0.05 & -0.08 & -0.05 & -0.03 & -0.07 & -0.02 & -0.01 \\
\hline Position & 0.51 & 0.29 & 0.32 & 0.10 & -0.04 & 0.36 & 0.15 & -0.04 & -0.02 \\
\hline Ownership & 0.16 & .09 & 0.12 & 0.05 & 0.01 & 0.08 & .01 & -0.05 & -0.05 \\
\hline $\begin{array}{c}\mathrm{HR} \\
\text { practices }\end{array}$ & & $0.57^{* * *}$ & & $\begin{array}{c}0.55^{* *} \\
*\end{array}$ & $0.28 * * *$ & & $0.52 * * *$ & $\begin{array}{c}0.15 * * \\
*\end{array}$ & 0.06 \\
\hline $\begin{array}{l}\text { Psychologi } \\
\text { cal } \\
\text { empowerm } \\
\text { ent }\end{array}$ & & & & & $0.48 * * *$ & & & $\begin{array}{c}0.65^{* *} \\
*\end{array}$ & $0.51^{* * *}$ \\
\hline $\begin{array}{l}\text { Intrinsic } \\
\text { motivation }\end{array}$ & & & & & & & & & $0.31 * * *$ \\
\hline $\mathrm{R} 2$ & $0.35^{* * *}$ & $0.61 * * *$ & $0.14 * * *$ & $\begin{array}{c}0.39 * * \\
*\end{array}$ & $0.48^{* * *}$ & $\begin{array}{c}0.17 * * \\
*\end{array}$ & $0.39 * * *$ & $\begin{array}{c}0.55^{* *} \\
*\end{array}$ & $0.60 * * *$ \\
\hline$\Delta \mathrm{R} 2$ & $0.34 * * *$ & $0.60 * * *$ & $0.13 * * *$ & $\begin{array}{c}0.39 * * \\
*\end{array}$ & $0.47 * * *$ & $\begin{array}{c}0.16^{* *} \\
*\end{array}$ & $0.38 * * *$ & $\begin{array}{c}0.54 * * \\
*\end{array}$ & $0.59 * * *$ \\
\hline $\mathrm{F}$ & $\begin{array}{c}42.58 * * \\
*\end{array}$ & $\begin{array}{c}108.35 * \\
* *\end{array}$ & $\begin{array}{c}13.45^{* *} \\
*\end{array}$ & $\begin{array}{l}44.25^{*} \\
* *\end{array}$ & $\begin{array}{c}55.43^{* *} \\
*\end{array}$ & $\begin{array}{c}15.98^{*} \\
* *\end{array}$ & $\begin{array}{c}43.00 * * \\
*\end{array}$ & $\begin{array}{c}73.17 * \\
* *\end{array}$ & $79.40 * * *$ \\
\hline
\end{tabular}

\section{Discussion}

The primary theoretical contribution of this research is providing a better understanding of the etiology of employee engagement. According to Kahn (1990) and Rich (2010), Engagement is rooted in the psychological conditions, and the perceptions of work context cause those psychological conditions. But they didn't explain why psychological condition impact employee engagement. We extended Kahn's and Rich's theory by considering psychological need satisfaction and intrinsic motivation serve as important mechanisms through that the perceived HR practices impact employee engagement from self-determination perspective.

Based on theoretically derived hypotheses, our findings do have practical implications as well. The research results provide evidence that HR practices enable firm to fuel employee engagement. It is important that employees view their perception of human resource practices as a source of psychological empowerment and high intrinsic motivation related to engagement and better job performance. Furthermore, the desirable attitudes and motivate behaviors that facilitate service quality leading to customer satisfaction and loyalty are important resources of competitive advantage. 


\section{Limitations and Directions for Future Research}

We acknowledge that the study has several limitations. First, the cross-sectional design of the research precludes any causality relationship. Longitudinal research that examines the relationship between HR practices and important outcomes over time may provide the nature of the causality relationships and realize the benefits of the work systems. Second, we collected data from employee and the single source lead to common variance inevitably, and multi-source of date should be gathered in future research. Third, we focus on the employee perceived HR practices in this study and examined the relationship in the micro level. Employee engagement in the work is a social phenomenon. And an important direction for future research is to developing multilevel model to examine the impact and influence processes of HR practices on outcomes at both the individual and unit levels.

\section{Reference}

[1] W.A. Kahn, To be fully there: Psychological conditions of personal engagement and disengagement at work .The Academy of Management Journal. 33(1990) 692-724.

[2] B.L. Rich, J.A. Le Pine, and E.R. Crawford, Job engagement: Antecedents and effects on job performance Academy of Management Journal. 53(2010)617-635.

[3] J.K. Harter, F.L. Schmidt, S. Agrawal and M.A. Plowman, Q12 meta-analysis: The relationship between engagement at work and organizational outcomes, NE: Gallup(2012).

[4] J. Loehr and T. Schwartz. The power of full engagement: Managing energy, not time, is the key to high performance and renewal. New York: Free Press, 2003.

[5] Gallup. State of the global workplaces: employee engagement insights for business leaders worldwide(2013).

[6] K. Alfes, A.D. Schantz, C. Truss and E.C. Soane, The link between perceived human resource management practices, engagement and employee behaviour: a moderated mediation model, The International Journal of Human Resource Management. (24)2013 330-351.

[7] J. P. Meyer and M. Gagne, Employee engagement from a self-determination theory perspective, Industrial and Organizational Psychology. 1(2008) 60-62.

[8] H .Liao, K. Toya, D. P. Lepak and Y. Hong, Do they see eye to eye? Management and employee perspectives of high-performance work systems and influence processes on service quality, Journal of Applied Psychology, 94(2009) 371-391.

[9] S. Aryee, F.O. Walumbwa, E.Y. M. Seidu and L.E. Otaye, Impact of High-Performance Work Systems on Individual and Branch-Level Performance: Test of a Multilevel Model of Intermediate Linkages, Journal of Applied Psychology. 97(2012)287-300.

[10] R.M. Ryan and E.L. Deci, Self-determination theory and the facilitation of intrinsic motivation, social development, and well-being, American psychologist. 55(2000)68-78.

[11]D. Liu, S. Zhang, L. Wang and W.L. Thomas, The effects of autonomy and empowerment on employee turnover: Test of a multilevel model in teams, Journal of Applied Psychology. 96(2011) 1305-1316.

[12] J.P. Meyer, M. Gagne and N.M. Parfyonova, Toward an evidence-based model of engagement: what we can learn from motivation and commitment research, in Handbook of Employee Engagement: Perspectives, Issues, Research and Practice, Edward Elgar Publishing Inc., UK, 2010, pp.62-73. 
[13]X.M. Zhang and K.M. Bartol. Linking empowering leadership and employee creativity: The influence of psychological empowerment, intrinsic motivation, and creative process engagement, Academy of Management Journal, 53(2010)107-128.

[14] N. Weinstein and R.M. Ryan, When helping helps: autonomous motivation for prosocial behavior and its influence on well-being for the helper and recipient, Journal of personality and social psychology. 98(2010) 222-244.

[15]M. Gagne and E.L. Deci. Self-determination theory and work Motivation, Journal of Organizational Behavior. 26(2005) 331-362.

[16]L.Y. Sun, S. Aryee and K.S. Law, High performance human resource practices, citizenship behavior, and organizational performance: A relational perspective, Academy of Management Journal. 50(2007) 558-577.

[17]G.M. Spreitzer. Individual empowerment in the workplace: Dimensions, measurement, validation, Academy of Management Journal. 38(1995) 1442-1465.

[18] M.A. Tremblay, C.M. Blanchard and S. Taylor, Work Extrinsic and Intrinsic Motivation Scale: Its value for organizational psychology research, Canadian Journal of Behavioural Science. 41(2009) 213-226.

[19]D. Liu, X.P. Chen and X. Yao. From autonomy to creativity: A multilevel investigation of the mediating role of harmonious passion, Journal of Applied Psychology. 96(2011)294-309. 